\title{
LA SITUACIÓN DE LA ANOTACIÓN EN LAS REDES SOCIALES DEL LIBRO EN INTERNET (2007-2014)*
}

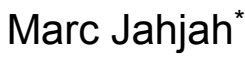

RESUMEN: Desde 2008, las nuevas redes sociales de lectores han crecido (BookGlutton, Kindle Highlights, Readmill, etc.). Ofrecen a sus usuarios la posibilidad de anotar libros y compartir sus reflexiones a través de dispositivos electrónicos (tabletas, ordenadores, etc.) o interfaces de escritura. Estas escrituras en los márgenes (marginalia) son recogidas por compañías y explotadas de diversas maneras (usuarios de datos, libros enriquecidos, etc.). Este artículo intenta entender por qué la anotación es objeto de tanto interés por parte de los industriales de la lectura y cómo lo explotan ellos.

PALABRAS CLAVE: Redes Sociales. Lectura. Anotación. Libros Digitales. Internet.

Al lanzar en 2007 BookGlutton, Travis Adler inauguró un nuevo tipo de red social del libro en Internet: el lector ya no estaba solo invitado a producir una cierta cantidad de formas escriturales (críticas, citas, etc.) a partir de una ficha de libros, como ya era el caso con Librarything, Goodreads o Babelio (Imagen 1); se le llamaba ahora a tomar los "márgenes" de los programas de lectura (Imagen 2).

\footnotetext{
* Universidad Paris IV Sorbonne, France. E-mail: marc.jahjah@gmail.com 
Imagen 1 - Una "ficha" de libro en la red social Babelio en 2014

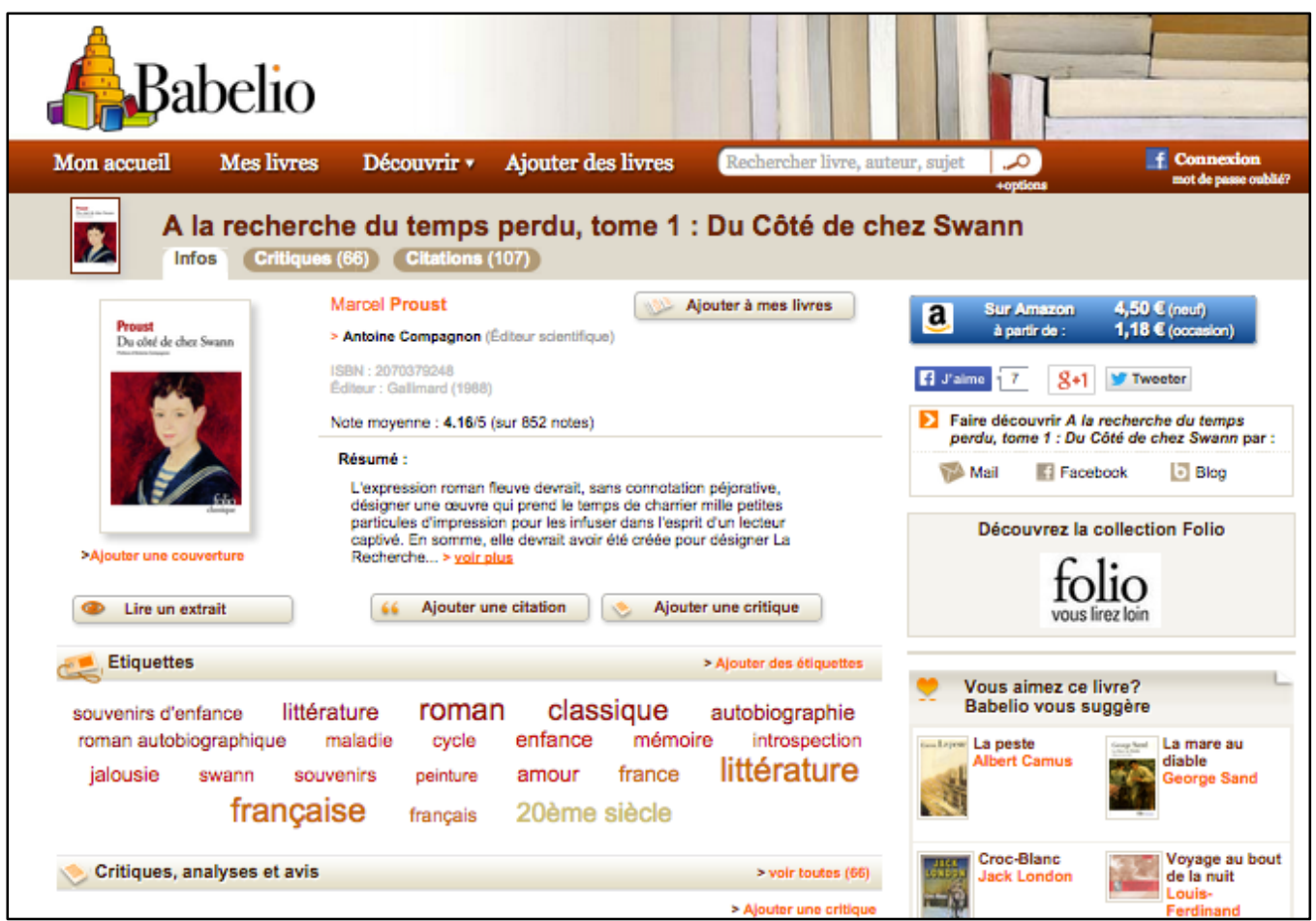

Fuente: <http://www.babelio.com/livres/Proust-A-la-recherche-du-temps-perdu-tome-1--Du-Cote-de/3063, 20/9/2014>.

Imagen 2 -El programa de anotación de BookGlutton a septiembre de 2013

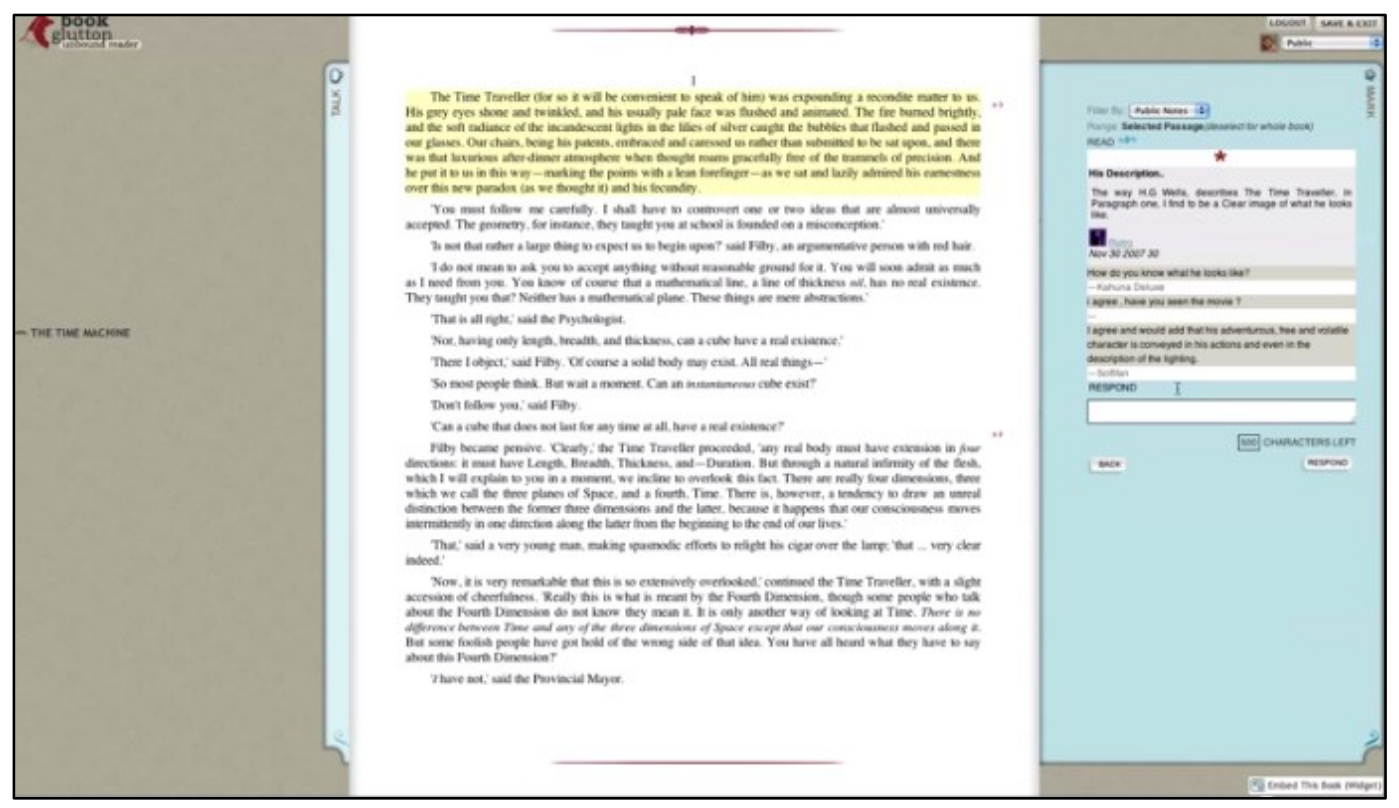

Fuente: Captura de pantalla a partir de un vídeo de presentación de la co-fundadora de BookGlutton (Travis Alber): <https://www.youtube.com/watch?v=dvKpqhDnuh0>, 15 septiembre 2013. Fuente consultada a 20/9/2014. 
El lanzamiento del iPad en 2010 vino acompañado de una multiplicación de estas redes, que conocieron un cierto entusiasmo antes de perder popularidad algunos años más tarde con ocasión de la adquisición de Readmill en 2014 por Dropbox. No han emergido al mismo tiempo, no tienen las mismas dimensiones, ni los mismos medios ni objetivos. Todas, sin embargo, permiten anotar libros digitales y compartir las formas así producidas; movilizan igualmente todo un imaginario de formas de la cultura impresa y explotan los contenidos producidos por sus usuarios según diversas modalidades. Estas características autorizan a inscribirlas a la vez en una historia de la cultura del libro y en la de las industrias culturales.

El presente artículo estudia esta confluencia planteando una pregunta a priori simple: ¿cómo una forma de la cultura letrada (la anotación) ha podido atraer hasta este punto la atención de las industrias de la cultura digital? Antes de analizar sus imaginarios y las condiciones de emergencia de esta atracción, demostraré que estos dispositivos aparentan siempre inscribirse en la continuidad de la cultura impresa, mientras someten la anotación a transformaciones profundas que afectan tanto a la identidad de los actores editoriales como a las condiciones de elaboración y de circulación de conocimientos.

\section{Espacios engañosamente familiares y amistosos}

\subsection{Formas materiales estereotipadas}

A priori, nada ha cambiado: cuando se encuentra en un dispositivo ${ }^{1}$ de lectura denominada "social", el lector está en un entorno familiar. Las redes del libro en Internet tienden a convocar ${ }^{2}$ un conjunto de signos y de formas materiales ${ }^{3}$

\footnotetext{
${ }^{1}$ Se trata de dispositivos en la medida en que pueden estar compuestos de un conjunto de objetos (programas que recogen anotaciones producidas por usuarios, páginas web que las recogen, páginas de Twitter o Facebook que aseguran su promoción, etc.).

2 La convocatoria es lo que evoca, "por el juego de coocurrencias y de isotopías, de formas familiares". (CANDEL, 2013, p. 46)

3"formas propuestas al usuario" que "apelan a la memoria de las materialidades de la cultura". (JEANNERET, 2012, p. 398)
}

Texto Digital, Florianópolis, Santa Catarina, Brasil, v. 12, n. 2, p. 96-123, jul./dez. 2016. ISSNe: 1807-9288. 
estereotipadas que connotan 4 la cultura libresca y letrada, para eliminar las reticencias técnicas y culturales que afectan al recurso de herramientas informáticas.

Una de las manifestaciones de estas formas esperadas concierne al libro. Los logos de Readmill, Kobo y Amazon remiten así a una memoria colectiva y material inmediatamente identificable (Imagen 3, Imagen 4, Imagen 5). El primero representa un marcapáginas, que permite identificar sin ambigüedad un libro; el segundo un doblez, que domina el nombre de la empresa; el tercer logo, de Amazon, es una pequeña escena de lectura, en la que un joven lee bajo un árbol. Todos estos signos pertenecen a lo enciclopédico, es decir, a un conjunto de conocimientos estabilizados sobre el mundo que permiten reconocer sin dificultad un objeto que pertenece a nuestra memoria común. "La recurrencia de tales figuras pone de manifiesto que el libro como tema del discurso es primero objeto tangible, identificable en el mundo social según una serie de características concretas" (CANDEL, 2008, p. 104).

Imagen 3 - Logo de Readmill

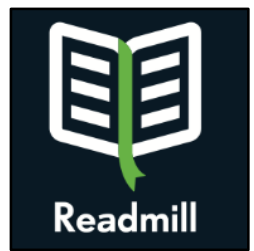

Fuente: https://readmill.com/, a 1/1/2014.

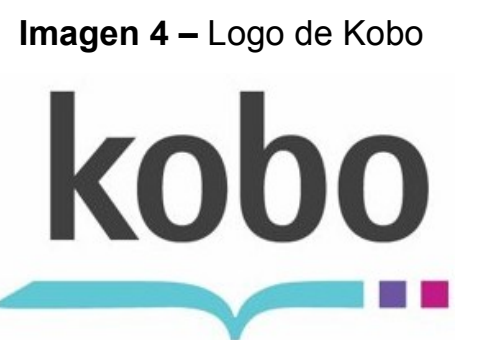

Fuente: captura de pantalla de la aplicación Kobo para iPad, a 10/5/2012.

\footnotetext{
${ }^{4}$ La connotación practica un juego de referencias que desplaza el sentido literal o se añade a él. Cfr. Driss Ablali et Dominique Ducard, Vocabulaire des études sémiotiques et sémiotiques, Paris, Honoré Champion, 2009.
} 
Imagen 5 - Logo del programa de anotación de Amazon

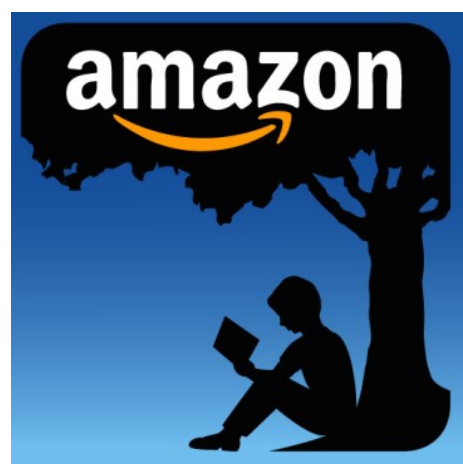

Fuente: captura de pantalla de la aplicación Kindle para iPad, a 10/8/2014.

Se encuentran igualmente semejantes signos en un conjunto de instrumentos de escritura diseminados. En su aplicación Kobo by Fnac, así como en su página destinada a la autopublicación, Kobo recurre por ejemplo a marcadores estereotipados de la cultura impresa:

Imagen 6 - Premio "Lecteur Auteurisé" de la aplicación Kobo by Fnac

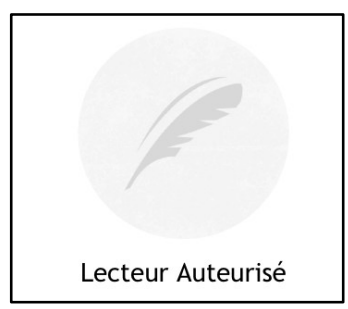

Fuente: captura de pantalla de la aplicación Kobo by Fnac para iPad, a 2/10/2013.

Imagen 7 - El logo de "Writing Life" de Kobo y Fnac

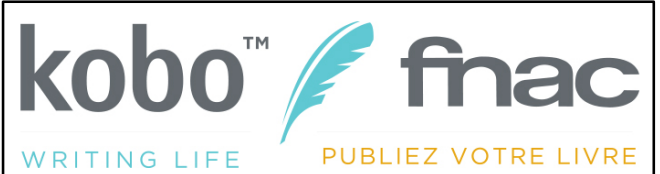

Fuente: http://fr.kobo.com/writinglife, a 5/7/2014.

Además de ser connotativo, este signo es metonímico: la pluma no solo alude a la actividad escritural sino al mundo cultural al que pertenece y al que Kobo aspira, en efecto; por sinécdoque la pluma terminará por designar al "gran escritor". Kobo promueve así una economía y una axiología de la escritura, como demuestra este otro banner: 
Imagen 8 - Banner «Kobo writing life»

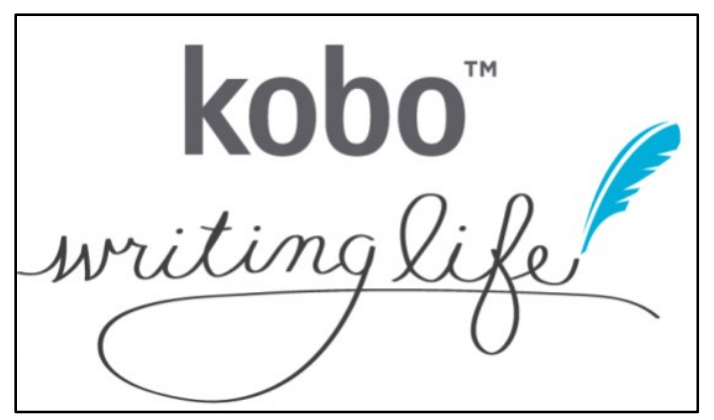

Fuente: <http://fr.kobo.com/writinglife>, a 5/7/2014.

La letra en cursiva, considerada como personal, es así asociada a un acto (la escritura ${ }^{5}$ ) cuyo trazo autentifica la práctica. Al estar "relacionado con su dimensión icónica" (CANDEL, 2007, p. 28), el texto se convierte en una imagen que consagra más al gesto que al mensaje. Se podría decir lo mismo de una forma presente en los índices de Kobo:

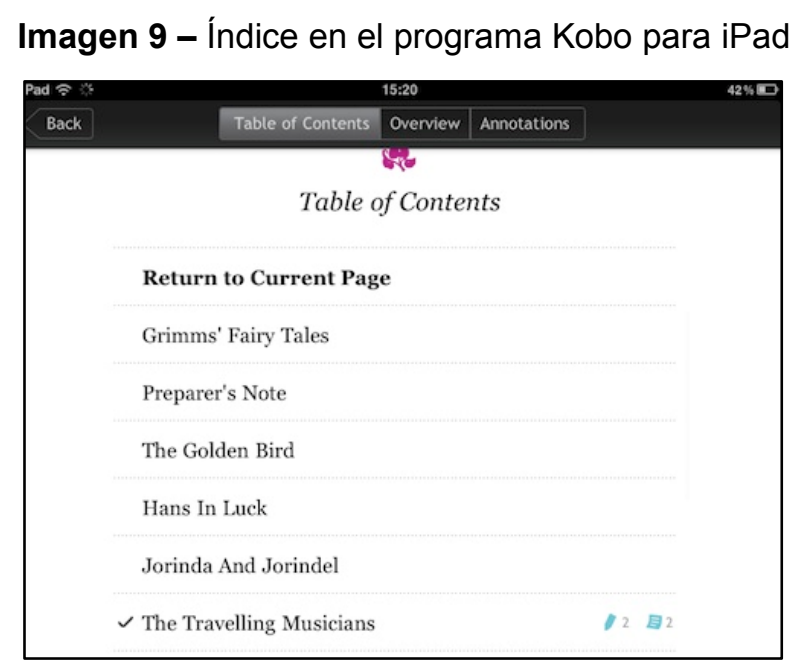

Fuente: Captura de pantalla a partir de la aplicación Kobo para iPad, a 2/09/2011.

Si no todos dominamos la tipografía para identificar un signo de principio de párrafo sobre la mención "Table of Contents", nuestra memoria material nos permite al menos reconocer un espacio familiar. El recurso a esta forma antigua indica que Kobo espera sacar de su convocatoria la legitimidad de la cultura tipográfica, capaz

${ }^{5}$ Sobre este tema, consultar el libro de referencia de Béatrice Fraenkel: La Signature. Genèse d'un signe, París, Gallimard, 1992.

Texto Digital, Florianópolis, Santa Catarina, Brasil, v. 12, n. 2, p. 96-123, jul./dez. 2016. ISSNe: 1807-9288. 
de producir formas complejas: importa más que el signo sea visto que identificado, porque acarrea todo un imaginario editorial. Al focalizar la atención sobre el espacio de lectura, es el marco material (los márgenes de la pantalla) el que debe supuestamente desaparecer o hacerse transparente.

\subsection{Puesta en escena de la intimidad y llamada a la participación}

Las redes del libro se presentan en efecto siempre bajo una apariencia de transparencia desnuda: no harían sino acoger las palabras y los pensamientos de los usuarios (Imagen 11) puestos en escena como bocadillos (Imagen 12 y 13), sin mediación alguna, sin afectar a las modalidades expresivas. El espacio, en esta retórica, se convierte en el supuesto lugar de la experiencia íntima, que toma prestado una vez más los estereotipos de la cultura textual: asociada, al menos desde el siglo XIV con Petrarca, a un diálogo del lector con el texto, la anotación y su intimidad sirven aquí a los intereses de un dispositivo cuya supervivencia depende más o menos, según los modelos económicos, de la producción de sus usuarios. De ahí las llamadas permanentes a la participación y a un aprovechamiento generalizado de la lectura colectiva ("read better together", Imagen 11) que imponen un paradigma participativo y una mitología conversacional supuestamente mejor adaptados a la lectura. En Open Margin, el espacio de escritura está así asociado a la liberación del lector: los márgenes del programa se presentan como un lugar de realización (Imagen 10), clásico del discurso de empowerment de la web 2.0 (BOUQUILLON; MATTHEWS, 2011).

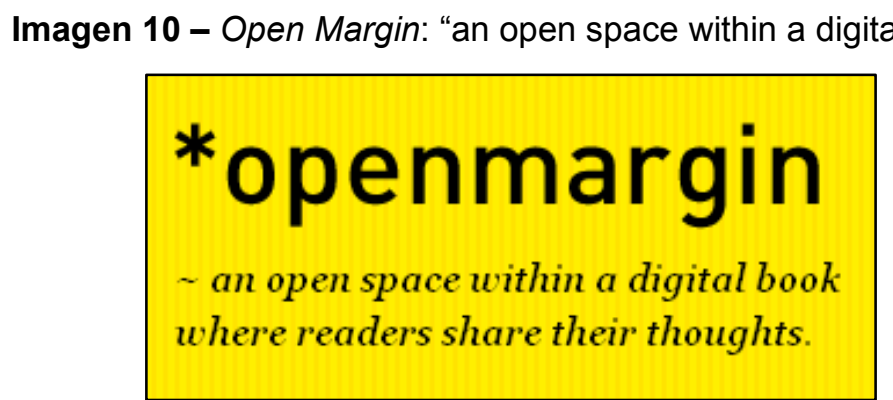

Fuente: <http://www.openmargin.com/>, a 3/7/2012. 
Imagen 11 - "read better together" con Copia

\section{LIVEIN THE MAREIIS}

Copia, a social eReading platform, connects you and your friends inside the books you need.

Buy books, take and share notes, start study

groups, join discussions, and read better together.

All inside the margins.

\section{SIEN UP NOW}

Fuente: http://www.thecopia.com, a 3/09/2013.

\section{Imagen 12 - Una puesta en escena del "pensamiento" íntimo en Copia}

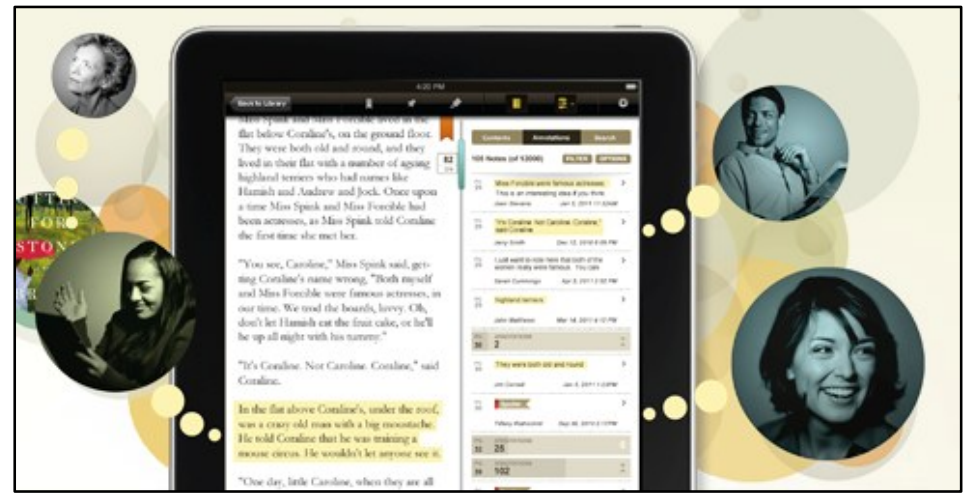

Fuente: <http://www.thecopia.com/home/index.html> en 2013. Captura de pantalla a 23/04/2013.

Imagen 13 - Un bocadillo en una imagen de BookGlutton

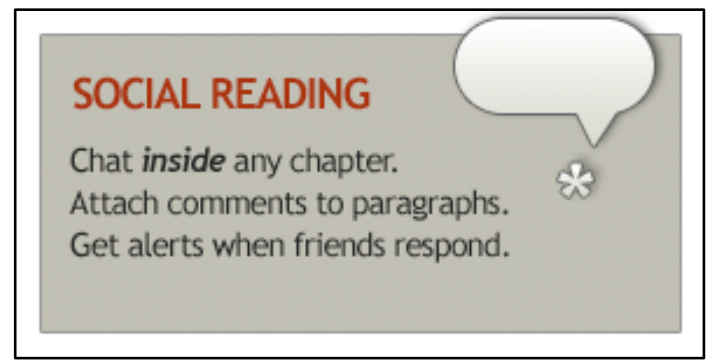

Fuente: <http://www.bookglutton.com/>, a 3/10/2012.

La puesta en escena de la intimidad y de la expresión personal toma la forma de una metáfora del espacio de lectura en Readmill, a través de dos modelos: el "club de lectura" y la "sala de lectura" (Imagen 16). Cada vez que un escritor produce una anotación, se informa automáticamente al usuario de su círculo relacional (recibe 
una alerta, Imagen 14) en el dispositivo de Readmill. Ahora bien, tales procedimientos pueden ser intrusivos y parasitar así el discurso de la intimidad que desea promover la empresa. La imagen de la sala de lectura permite paliar este problema: las notificaciones no son así sino un medio de informarse "desde los hombros de los amigos" (Imagen 16). Así desarticula los miedos a menudo asociados a este tipo de dispositivos, acusados de empañar la vida privada. Al contrario, Readmill recurre a metáforas espaciales para hacer de estos espacios lugares de convivencia, que resuelven la paradoja de la masificación, necesaria para el dispositivo, pero de la que desconfiaría el usuario, gracias a estrategias discursivas de desmasificación.

\section{Imagen 15 - Notificaciones en la página web de Readmill}

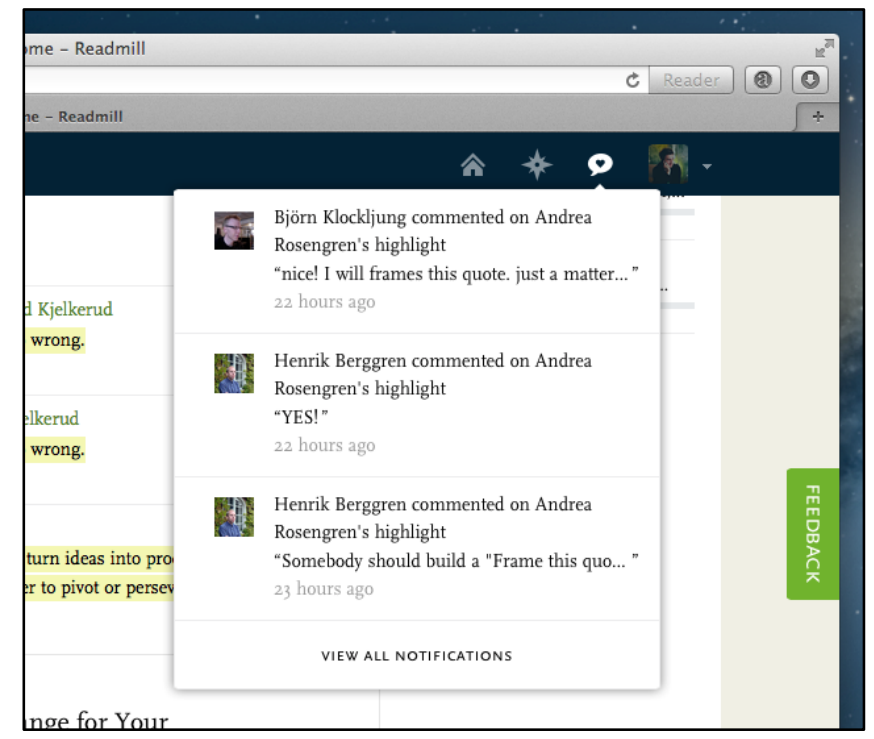

Fuente: <http://blog.readmill.com/post/40094322686/stay-in-the-loop-with-all-new-notifications>, a 23/08/2014.

Imagen 16 - "community highlights view" en el blog de Readmill

While our community highlights view makes for an instant book club in every book, your feed is a library reading room, where you can peek over the shoulders of friends and catch glimpses of books you wouldn't find otherwise.

Fuente: <http://blog.readmill.com/post/66184218374/a-new-way-to-read-together>, a 6/11/2013.

\section{Una regulación de la anotación y de su circulación}


Estos espacios son sin embargo engañosos, a pesar de su familiaridad aparente: la apropiación de formas materiales de la cultura letrada es proporcional a las transformaciones inéditas que ejercen asimismo sobre las anotaciones.

\subsection{Del subrayado a la cita: lecturas indiciales}

El análisis de circulaciones transmediáticas permite demostrarlo. Véase este pasaje subrayado a partir del programa Kindle para iPad:

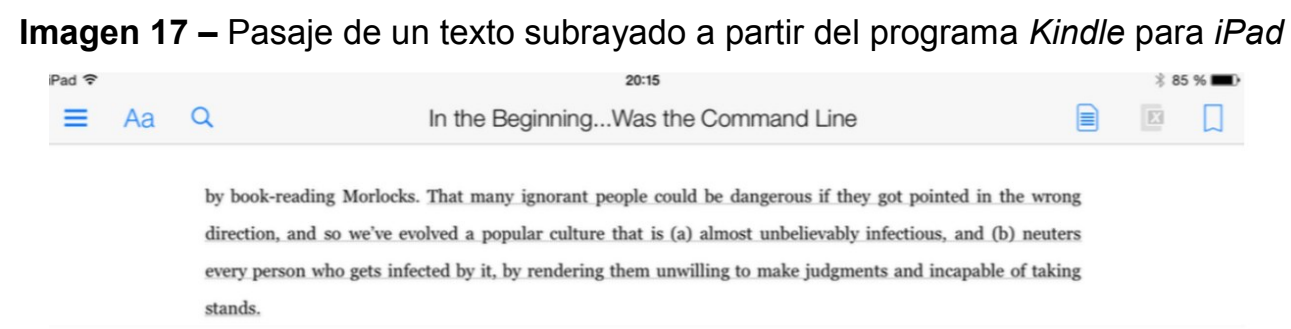

Fuente: captura de pantalla realizada a 10/08/2014.

Lo volvemos a encontrar en una ficha de libros de Amazon.fr:

Imagen 18 - El mismo pasaje en Amazon.fr, subrayado por x usuarios más

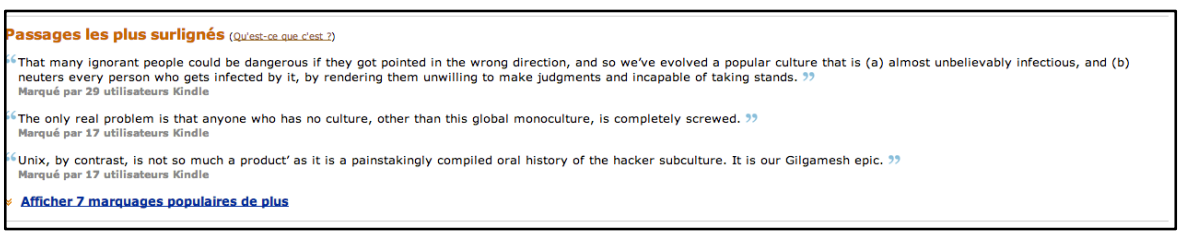

Fuente: captura de pantalla realizada a 10/08/2014.

Creemos estar frente al mismo pasaje, pero la primera imagen muestra un subrayado y la segunda una cita. Gráficamente no son los mismos enunciados: las comillas iconizadas acompañan la cita que aparece y se reconoce entonces como tal. Su introducción es asunto de Amazon, que despoja automáticamente al enunciador de su enunciado: marcas de localización en un primer caso, las anotaciones se convierten luego en contenidos editoriales, que alimentan la página de Amazon, tanto para mejorar las referencias de esas páginas en los motores de búsqueda como para incitar a la compra gracias a extractos consensuados de libros. 
La potente maquinaria silenciosa de Kindle transforma así un simple subrayado en cita, haciéndola entrar en el régimen de las lecturas indiciales:

\begin{abstract}
los formatos cortos ofrecen a la navegación personal selecciones muy someras que permiten hacerse una idea de un contenido (un vídeo, un trailer, un consejo de lectura, un post, un tweet) sin haber accedido a él directamente. Es lo que se llama la "lectura indicial" y constituye sin duda una prolongación inesperada de esta multiplicación de las formas de selecciones personales que denominamos apropiación. El régimen de atención que le corresponde es el que he designado como "alerta" para oponerlo a la fidelización, que es en realidad cualquier lectura de largo alcance (BOULLIER, 2012, p. 42).
\end{abstract}

\title{
2.2 Una planificación de la intimidad de la lectura
}

Estas máquinas automatizadas pueden igualmente facilitar la creación de auténticos cronotopos, este "universo de espacio y de tiempo que se desarrolla a partir de una forma mediática y por los textos que ella propone" (JEANNERET, 2014, p. 10). Así, tras haber producido un cierto número de subrayados con el programa Readmill para iPad, se propone al usuario recogerlos automáticamente en una línea de tiempo espacializada: 
Imagen 19 - "Línea de tiempo" de las anotaciones producidas con el programa Readmill

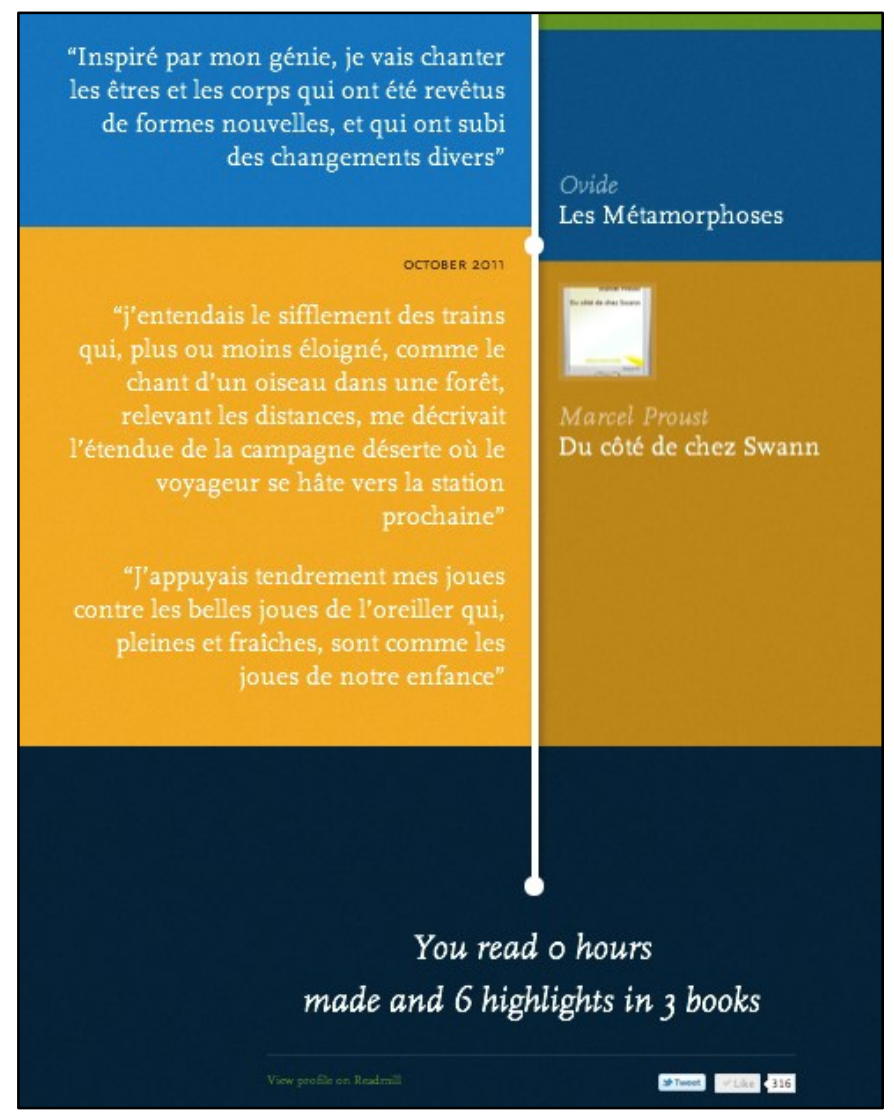

Como en Amazon, los pasajes subrayados son primero objeto de una transformación gráfica: las comillas les acompañan para hacerlos citas. Se organizan entonces en una toposintaxis. Cada uno de estos extractos está en efecto comprendido en encuadres que tienen una función indexical y relativa (BÉGUINVERBRUGGE, 2006): delimitan cada unidad textual del resto, pero convergen gráfica y linealmente en la misma indicación "You read 0 hours made and 6 highlights in 3 books". La imagen editorializa y recoge una materia dispar en una misma unidad gráfica inmediatamente perceptible y comunicable, mientras que las anotaciones son tenidas por personales y difíciles de explicitar, fuera de su espacio de contextualización. Esta recontextualización significante se debe aquí a la reorganización espacial de las anotaciones, que sirve para ordenar una materia considerada compleja y volverla visible cara a una audiencia exterior. 
Esta práctica antológica no es evidentemente nueva 6 , pero "en su despliegue digital, desarrolla una nueva configuración epistemológica y formal, capaz de reorientar nuestra apreciación de las relaciones entre saber y poder" (DOUEIHI, 2011, p. 164). En el caso de Readmill, por ejemplo, la anotación se reduce a algunas indicaciones estadísticas ("6 highlights in 3 books") como si las cifras pudieran por sí solas reducir la complejidad de esta práctica.

\subsection{Una actividad escritural enmarcada e industrializada}

Todo dispositivo técnico y editorial permite recoger anotaciones y tratarlas de forma automática, de forma que se eviten al máximo los usos marginales en la medida en que los contenidos son explotados por las estrategias comerciales de marketing. El usuario evoluciona así en un espacio documental que organiza y encuadra sus percepciones y acciones. Este espacio es asimismo comprendido en un conjunto de marcos ensamblados:

Imagen 20 - Los diferentes marcos de un dispositivo de lectura en pantalla ${ }^{7}$

Marco material

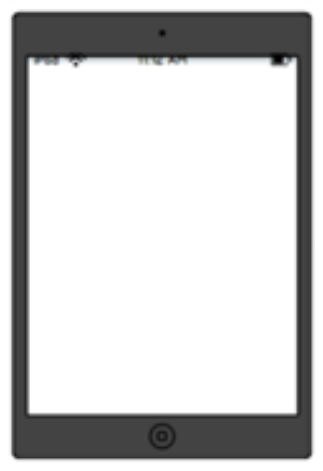

Marco del sistema Marco del programa

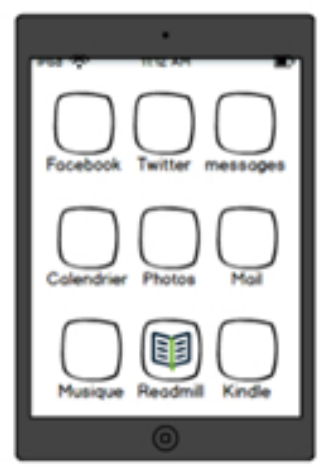

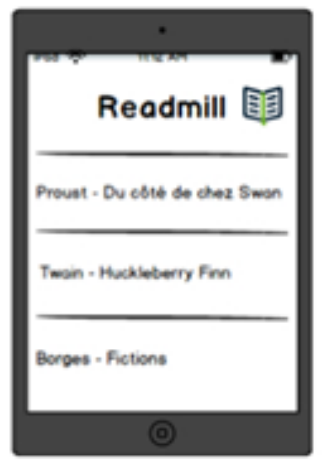

Marco del documento

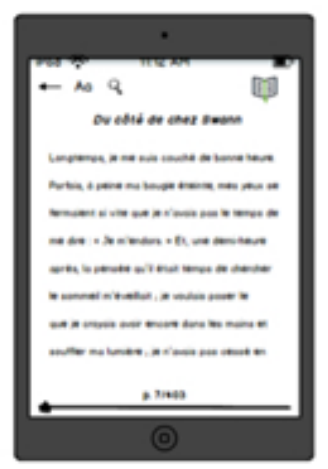

\footnotetext{
${ }^{6}$ Desde el siglo XII europeo, los compendios se desarrollaron para satisfacer las necesidades de la lectura "rápida" de los estudiantes (ROUSE; ROUSE, 1989; ILLICH, 1991). Estos conjuntos documentales no habrían sido sin embargo posibles sin el perfeccionamiento de las tecnologías de navegación, que permitían encontrar el extracto. Del siglo XV al XVIII, estas herramientas conocieron su punto álgido, mientras que un sentimiento surgió: el de una "sobrecarga de información" (Blair, 2011), a la que los editores respondieron con la multiplicación de antologías. Paralelamente, letrados virtuosos (como John Dee o los humanistas franceses; cfr. Sherman, 2008 y Châtelain, 1999) proporcionaron consejos técnicos a sus lectores para permitirles constituir sus propias herramientas (operaciones de extracción y de clasificación de la materia extraída, por ejemplo).

7 Esta ilustración ha sido concebida con el programa Balsamiq Mockups. Aquí me apoyo sobre las distinciones propuestas por Souchier (1999).
}

Texto Digital, Florianópolis, Santa Catarina, Brasil, v. 12, n. 2, p. 96-123, jul./dez. 2016. ISSNe: 1807-9288. 
Así, al marco material (tableta de Apple, por ejemplo) y al marco del sistema (iOS) sucede un marco del programa, que corresponde a las aplicaciones o programas disponibles para iPad, como Readmill. En este marco del programa, se encuentran al fin una multitud de otros marcos (marcos del documento o cajas) que se abren generalmente al activar un vínculo y permiten al usuario explotar la interfaz para producir inscripciones. En el programa del dispositivo Readmill, la creación de un subrayado o de una nota necesita primero que se seleccione un pasaje, lo que requiere tres gestos: clicar, mantener para delimitar, soltar (Imagen 21). Dicho de otro modo: ninguna inscripción puede hacerse sin marcar un elemento textual, es decir, sin anotación. El usuario debe entonces decidir entre tres "accionadores" (BOUCHARDON, 2012) o "botones":

Imagen 21 - Menú de producción de una anotación en el marco del programa Readmill para iPad

The old lady whirled round, and snatched her skirts out of danger. The lad fled on the instant, scrambled up the high board-fence, and disappeared over it.

His aunt Polly st Highlight Define Copy broke into a gentle langh.

|'Hang the boy, can't I never learn anything? Ain't he played me tricks enough like that for me to be looking out for him by this time? But old fools is the biggest fools there is. Can't learn an old dog new tricks, as the saying is. But my goodness, he never plays them alike, two days, and how is a body to know what's coming? He 'pears to know just how long he can torment me before I get my dainder up, and he knows if he can make out to put me off for a minute or make me laugh, it's all down again and I can't hit him a lick. I ain't doing my duty by that boy, and that's the Lord's truth, goodness knows. Spare the rod and spoil the child, as the Good Book says. I'm a laying up sin and suffering for us both, I know. He's full of the Old Scratch, but laws-a-me! he's my own dead sister's boy, poor thing, and I ain't got the heart to lash him, somehow. Every time I let him off, my conscience does hurt me so, and every time I hit him my old heart most breaks. Well-a-well, man that is born of woman is of few days and full of trouble, as the Scripture says, and I reckon it's so. He'll play hookey this evening [*'], and I'll just be obliged to make him work, to-morrow, to punish him. It's mighty hard to make

Una vez activado, el primer botón dirige a un nuevo marco-documento (Imagen 22). El texto subrayado aparece entonces en la parte superior; está acompañado de accionadores (los botones Facebook, Twitter, Mail; los botones Cancel y Done) así

Texto Digital, Florianópolis, Santa Catarina, Brasil, v. 12, n. 2, p. 96-123, jul./dez. 2016. ISSNe: 1807-9288. 
como de una llamada ("Comment on your highlight...") a producir una nota a partir del pasaje seleccionado.

Imagen 22 - Marco-documento de escritura en el marco-programa Readmill para iPad

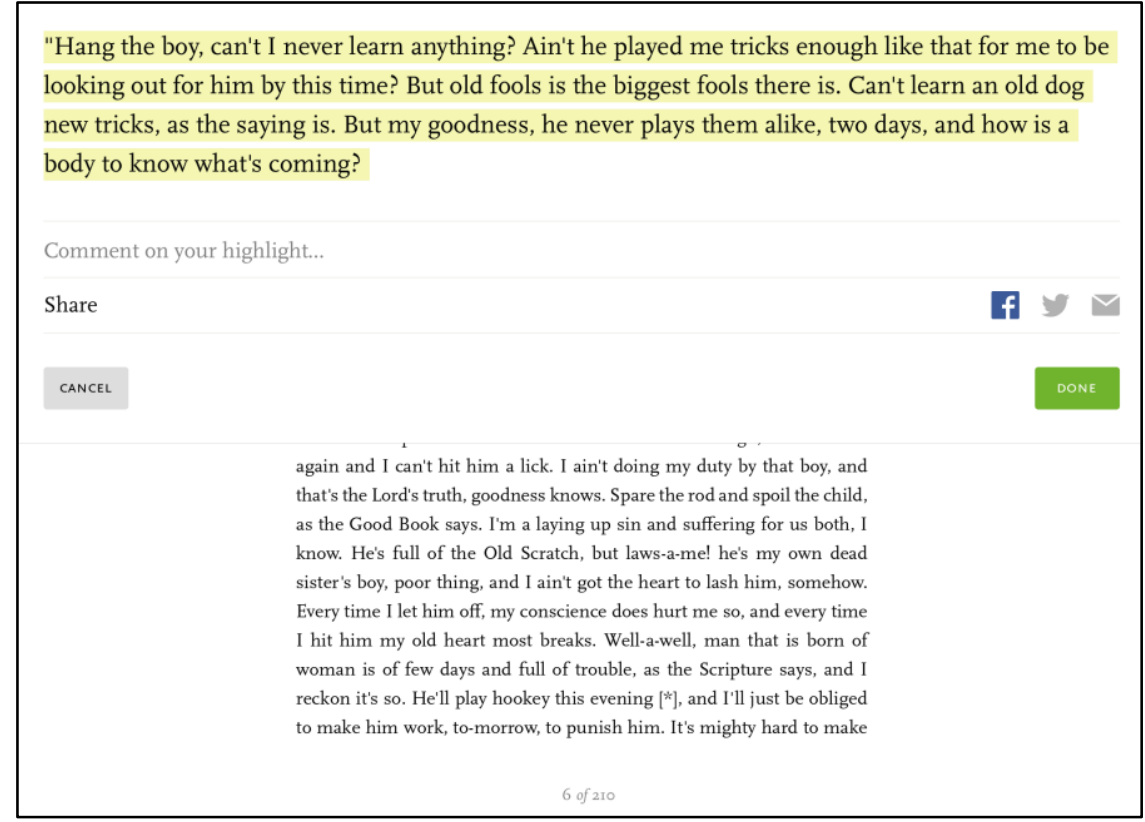

Los marcos de escritura toman prestados a la retórica clásica sus modos de persuasión de forma clara (BÉGUIN-VERBRUGGE, 2006): a la inventio (encontrar qué decir, como lo sugiere Readmill: "comment on your highlight") suceden así la dispositio (ordenar lo que se ha encontrado: el programa se encarga automáticamente con sus campos de entrada), la elocutio (u ornamentación, que corresponde aquí a los botones para compartir) y la actio (la parte dicha de un discurso: son las comillas que acompañan automáticamente todo extracto seleccionado). De la producción a la circulación, los marcos de escritura economizan la fuerza y el tiempo de trabajo; es por ello que industrializan (MCEGLIN, 2005, p. 252) las producciones discursivas e impiden los usos que se acercarían por ejemplo al grafiti ${ }^{8}$. Una anotación que ha circulado de un espacio a otro (del programa Kindle

\footnotetext{
8 Desde hace algunos años, los historiadores del libro y de las prácticas textuales se interesan a esta forma que ha sido abandonada, en beneficio de los marginalia (empleo indistintamente el término con "anotación": los marginalia no son sino la representación letrada de la anotación). En efecto, numerosos manuscritos y libros impresos contienen marcas que no se refieren necesariamente a un objetivo, es decir, a un texto comentado. Los escritores ocupan entonces el espacio de la página para dibujar (LERER, 2012), quejarse de una condición material (SCHOTT, 2012) o de una situación política (NIKOLOVA-HOUSTON, 2009). Interesarse en el grafiti es por tanto prestar atención a la
}

Texto Digital, Florianópolis, Santa Catarina, Brasil, v. 12, n. 2, p. 96-123, jul./dez. 2016. ISSNe: 1807-9288. 
a una ficha de libros Amazon.fr, por ejemplo) queda bajo el dominio de una función editor, en el sentido de editor (responsable de la presentación del texto) y de publisher (garante de la circulación del texto) (JEANNERET, 2014, p. 35).

\subsection{De la inscripción al dato o el grafiti imposible}

Cualquier otra forma (signos críticos) es imposible. Y con razón: solo las formas comercialmente explotables son valoradas por el dispositivo, esto es, los comentarios y los subrayados. El riesgo del solipsismo que acecha todo sistema semiótico está por lo demás contrarrestado por el modelo participativo, que tiene naturalmente un poder de reacción sobre la normalización de las anotaciones ${ }^{9}$, es decir, su comunicación eventual con un tercero. Estas operaciones tienen efectivamente un objetivo: asegurar la promoción del dispositivo fuera de su espacio, principalmente gracias a la diseminación de las producciones de los usuarios en las redes externas, como Twitter o Facebook; proveer de contenido editorial a menor coste (Amazon, Copia); informar sobre los comportamientos de lectura para venderlos a editoriales asociadas (Readmill) o mejorar la recomendación de libros a un usuario dado, en función de los pasajes anotados, de su rapidez de ejecución o de la hora a la que anota (Kobo).

\subsection{El trabajo de la identidad}

Para ello, el dispositivo necesita, por un lado, que las anotaciones sean inteligibles, más allá de su contexto de elaboración y que, por el otro, estén asociados a un escritor perfectamente identificado para que los riesgos de la interpretación se minimicen. La "identidad polifónica" (DOUEIHI, 2011, p. 94) de la cultura digital complica sin embargo esta identificación. Es por ello que las redes del libro han desarrollado todo un sistema de autentificación que atribuye un identificador a un usuario (ID,

relación antropológica que un escritor mantiene entre la escritura y el mundo. Cfr. Ragazzoli (2011), Scott-Warren (2010), Sherman (2009) et Brayman Hackel (2008).

${ }^{9}$ Wolfe et Neuwirth (2001) han demostrado, en efecto, que la socialización de las anotaciones trabaja su forma: uno se hace tanto más comprensible cuanto que se sabe leído.

Texto Digital, Florianópolis, Santa Catarina, Brasil, v. 12, n. 2, p. 96-123, jul./dez. 2016. ISSNe: 1807-9288. 
Imagen 25) para trazar con fiabilidad sus actividades y dar cuenta de ellas, por razones de marketing o jurídicas (Imagen 24). Así, "la homogeneización sociotécnica" conduce a "la homogeneización de las formas de comunicación y de presentación de sí" (GEORGES, 2011, p. 33).

Imagen 23 - Creación de un perfil en Readmill

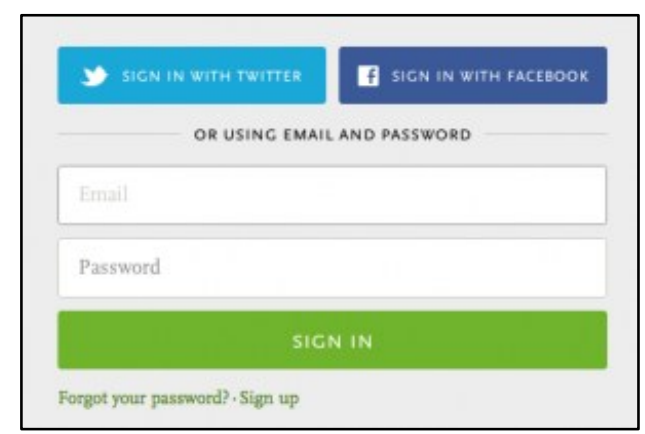

Imagen 24 - Cada libro está vinculado a un identificador único (aplicación Copia infra)

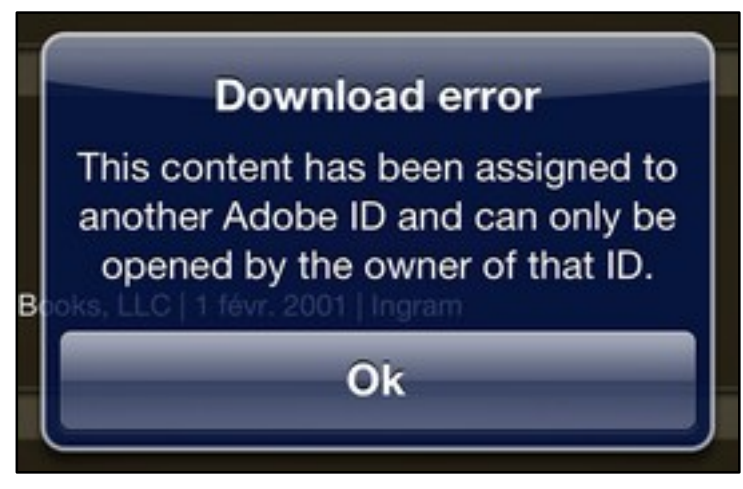

Imagen 25 - Crear un perfil en Open Margin

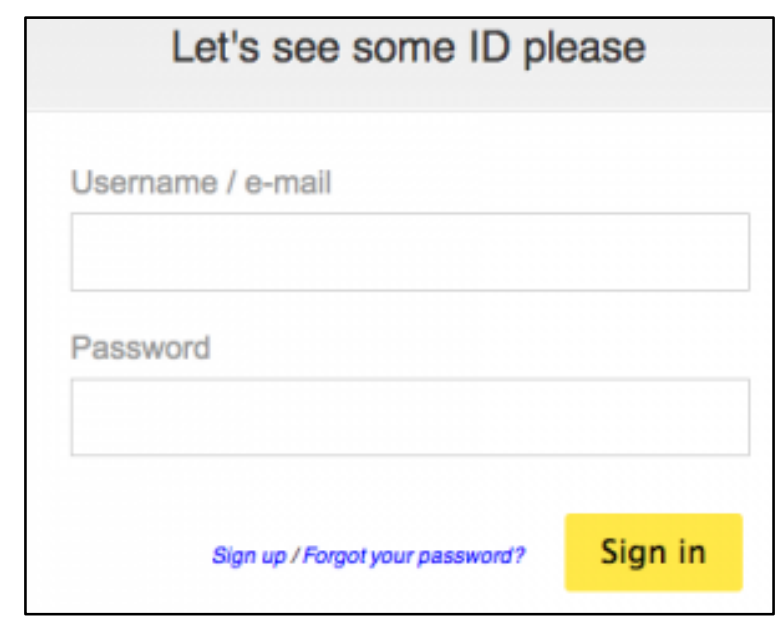

Texto Digital, Florianópolis, Santa Catarina, Brasil, v. 12, n. 2, p. 96-123, jul./dez. 2016. ISSNe: 1807-9288. 
A partir de ese momento, las anotaciones se convierten en índices potenciales de la personalidad del escritor y en signos de identificación. Es por ello que están ligadas a un perfil que toma la forma de un emblema ${ }^{10}$, i.e. una pequeña tabla que sirve de identidad y puede ser visitada, verificada, citada:

Imagen 26 - Identidad iconizada en Readmill

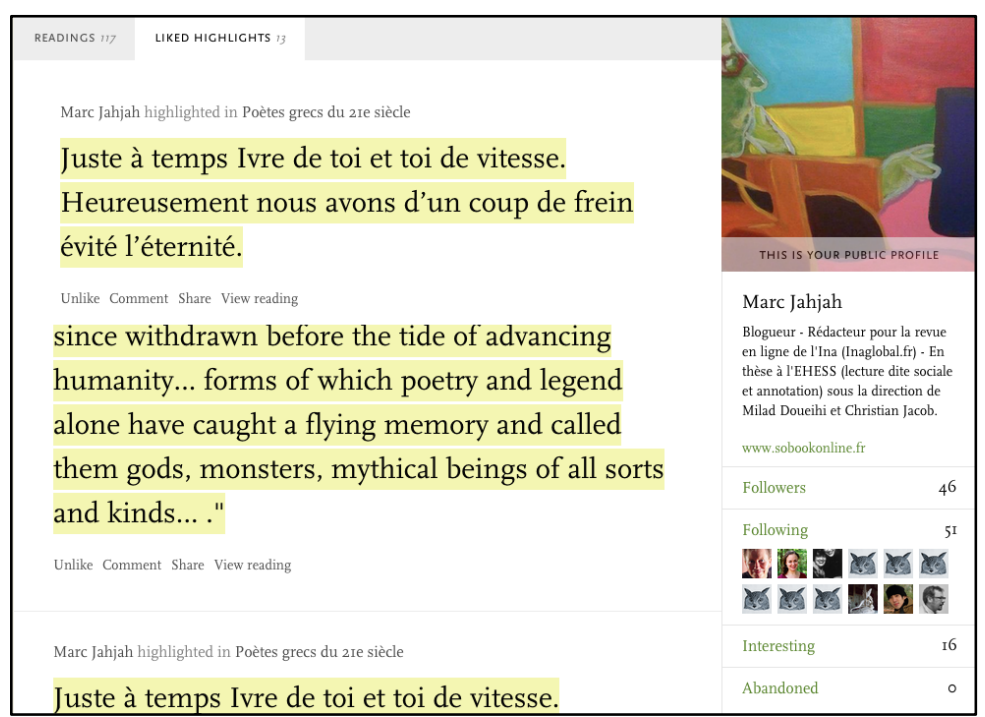

Fuente: <http://www.readmill.com/marc.jahjah>, a 01/08/2014.

Inscripciones ${ }^{11}$, las anotaciones se convierten así en índices y rastros $^{12}$, que son objeto de una búsqueda que los transforma en datos. La anotación es el instrumento privilegiado de esta transformación porque implica siempre un "acto de puesta en comunicación" (TURA, 2005) entre diferentes unidades textuales ${ }^{13}$ y un escritor, contrariamente al grafiti: posee entonces un alto grado de indicialidad, necesario a los dispositivos para hacer recomendaciones o analizar los comportamientos de los usuarios.

\footnotetext{
${ }^{10}$ Para una perspectiva histórica de esta noción, cfr. Michel Pastoureau, Une histoire symbolique du Moyen Âge occidental, París, Seuil, col. "Points Histoire", 2014.

11 Depósito "de signes ou de formes significatives sur un support quelconque" (LAUFER, 1989, p.11).

12 Sobre estas cuestiones, cfr. Yves Jeanneret, "Complexité de la notion de trace. De la traque au tracé" in Béatrice Galinon- Mélénec (dir.), L'Homme-trace : perspectives anthropologiques des traces contemporaines, París, Éditions du CNRS, p. 59-86, 2011.

13 Bringay et al. (2004) definen en efecto la anotación como una "note particulière attachée à une cible. La cible peut être une collection de documents, un document, un segment de document (paragraphe, groupe de mots, mot, image ou partie d'image, etc.), une autre annotation. $\grave{A}$ une annotation correspond un contenu, matérialisé par une inscription, qui est une trace de la représentation mentale que l'annotateur se fait de la cible. Le contenu de l'annotation pourra être interprété à son tour par un autre lecteur. Nous appelons l'ancre ce qui lie l'annotation à la cible (un trait, un passage entouré, etc.)" (p. 193).
}

Texto Digital, Florianópolis, Santa Catarina, Brasil, v. 12, n. 2, p. 96-123, jul./dez. 2016. ISSNe: 1807-9288. 


\subsection{La anotación como recurso informático}

El análisis de la documentación técnica de un dispositivo como Readmill (Imagen 27) que especifica desde el punto de vista informático las relaciones entre usuario y sus producciones, permite demostrar lo siguiente.

Imagen 27 - Código de "Get Highlights" en la página API de Readmill.

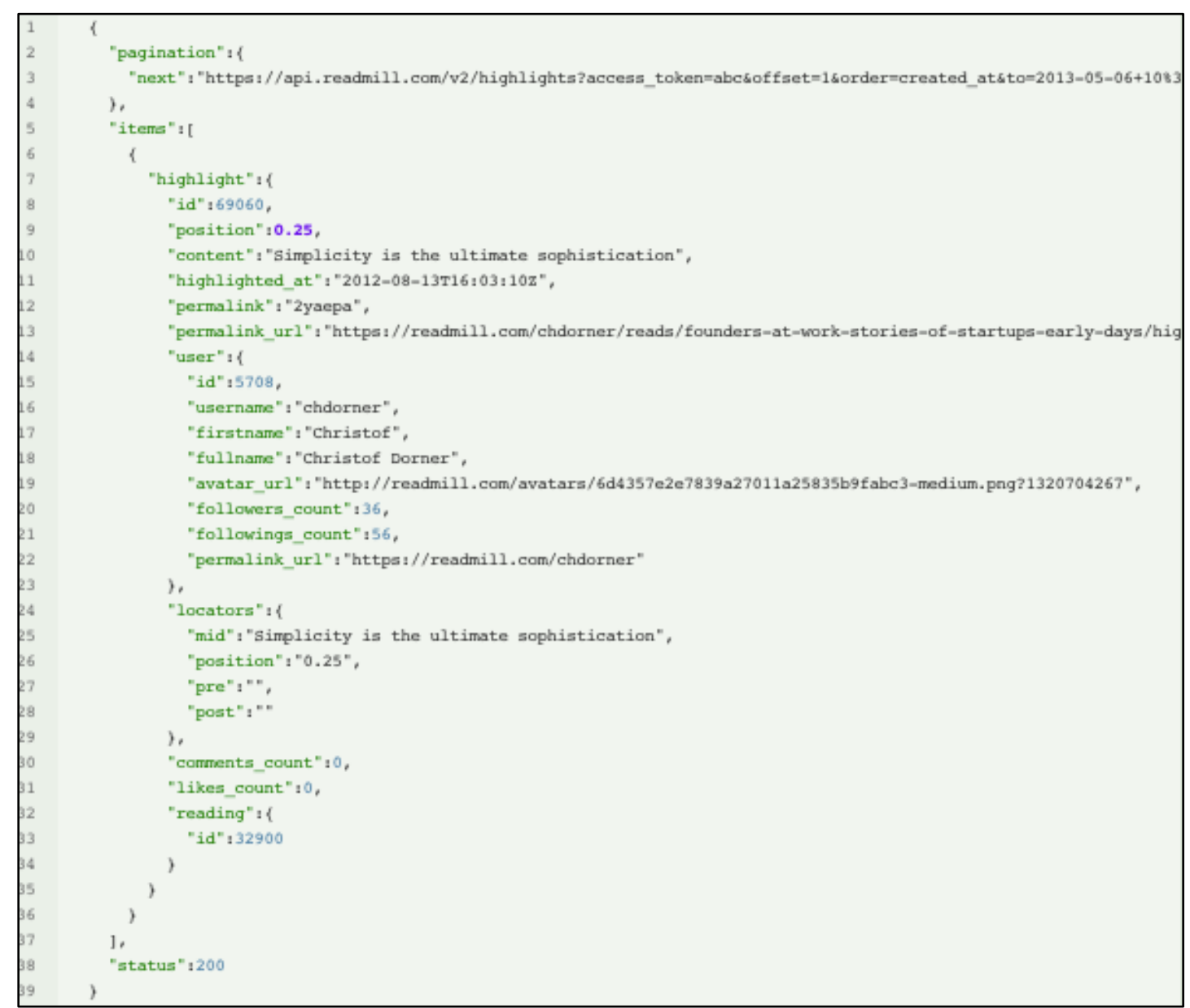

Fuente: <http://www.developers.readmill.com/api/docs/v2/get/highlights.html>, a 20/04/2013.

Cada pasaje subrayado ("highlight", línea 7), calificado de "contenido" (línea 10), está vinculado a un usuario (“id", línea 15) cuya identidad se reduce a un apellido/nombre, a un avatar (línea 19) y a un conjunto de relaciones sociales ("seguidores" / "siguiendo", líneas 20 y 21). Tiene relación por tanto con las relaciones entre unidades que pueden ser combinadas entre ellas. Cada una de esas unidades es un recurso en el sentido informático, es decir, un identificador dotado de una identidad estable (una URI). Ahora bien, una URI puede tener varias 
representaciones (MONNIN, 2012): una página del Monde.fr tiene una URL (una de las formas de URI), un referente identificable estable, pero puede tomar formas variadas, según sea visualizada en un ordenador o un teléfono. Del mismo modo, un subrayado puede tener representaciones diferentes en el programa de Kindle para iPad y el sitio Amazon.fr. Pero en tanto que recurso, posee un identificador estable.

\subsection{Los márgenes son otro canal del marketing}

La memoria material identificada más arriba no es sino un revestimiento semiótico del código informático: lo fenomenaliza adaptándolo a nuestros códigos culturales. Una vez que se le despoja de sus vestimentas, la anotación y los márgenes aparecen como lo que son, al menos para los industriales: tan solo recursos productivos y canales de marketing (Imagen 28). Sirven para recoger inscripciones, que serán objeto de una explotación muy amplia, desde el análisis cuantitativo a la organización de chat con un autor (Imagen 29).

Imagen 28 - "Margins Promotions are another marketing channel" según Sol Rosenberg de Copia

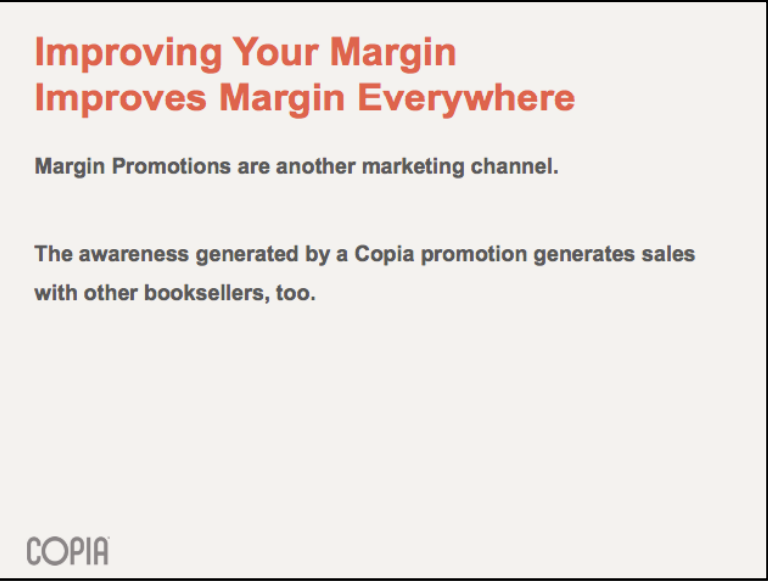

Fuente: Sol Rosenberg et Seth Kaufman, "Improving your margins", Tools of Change 2013, <http://www.toccon.com/toc2013/public/schedule/detail/28508>. EI PDF de presentación está disponible en esta dirección: http://www.toccon.com/toc2013/public/schedule/detail/28508. 
Imagen 29 - "How to use your marking to create added value."

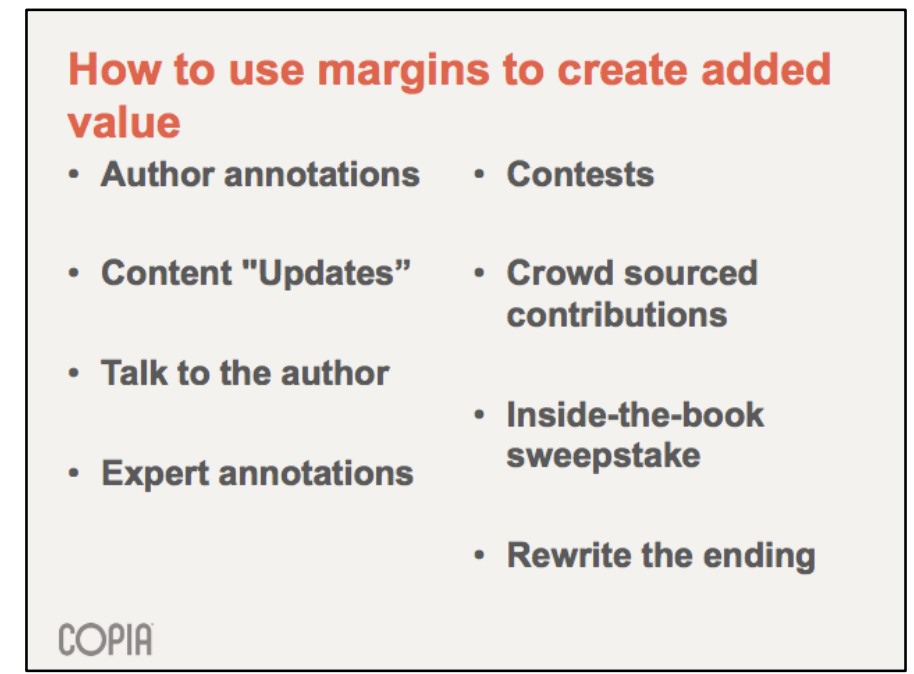

Fuente: Sol Rosenberg et Seth Kaufman, "Improving your margins", Tools of Change 2013, $<$ http://www.toccon.com/toc2013/public/schedule/detail/28508>. El PDF de presentación está disponible en esta dirección: http://www.toccon.com/toc2013/public/schedule/detail/28508.

\subsection{El encuentro de las industrias de web y de edición digital}

¿A qué se debe esta explotación de las producciones de los usuarios, así como el conjunto de discursos concerniendo sus emancipaciones gracias a su participación? Al encuentro de las industrias de web y de edición digital, orquestada por el inventor de la expresión "Web 2.0": Tim O’Reilly. En 2003, tras el crash de la bolsa, el emprendedor se pregunta qué características han permitido que ciertas empresas se salven. Un denominador común emerge: la participación de los usuarios, convertidos en actores de pleno derecho:

\footnotetext{
Mientras el sentido común y muchos especialistas consideran la Web 2.0 más bien desde el punto de vista de la cultura participativa, su historia muestra que se trata de una tentativa de restaurar la imagen de la Web y de sus empresas a los ojos de diversos actores políticos pero, sobre todo, económicos. Particularmente se pone en el punto de mira para esta campaña a los actores de la esfera financiera, inversores, bancos, consejeros. (BOUQUILLION; MATTHEWS, p. 7)
}

La articulación entre los actores económicos y culturales pasa entonces principalmente por la «culturización de la economía»" (p. 32) que consiste en dotar a estas marcas de un capital cultural. A partir de entonces, "cualquier producto puede ser asociado a una música, a una película" (p. 32), un libro o una anotación. Así, en 2012, Michael Serbinis, directivo del dispositivo Kobo, firmó una asociación con 
Starbucks ${ }^{14}$. A cambio de un café gratuito, los usuarios eran animados a leer para dejar suficientes rastros de lectura susceptibles de determinar su perfil.

Sin duda, nada materializa mejor esta convergencia entre los diferentes sectores industriales que la salida del iPad en 2010. Serbinis, entonces directivo de Kobo, redactó un poema que celebraba esta llegada como la de Cristo ${ }^{15}$.

Todas las confesiones se encuentran así representadas, pertenezcan a desarrolladores, editores, comerciales o especialistas del marketing. El iPad parecía entonces resolver sus diferencias porque la tableta debía "trascenderlas". La convergencia de sectores y actores constituye los dos polos de la web colaborativa que hace la "apología de las formas presentes del capitalismo" (BOUQUILLON; MATTHEWS, p. 51) al alabar la figura del "amateur-creador de contenidos" que permitiría trastocar el orden de las industrias clásicas de la cultura. En su artículo fundador de 2005 ${ }^{16}$, Tim O'Reilly considera así a los usuarios como "codesarrolladores": la gestión de la "inteligencia colectiva" se convirtió en el modelo de toda una economía.

En 2006, Tim O'Reilly organizó una conferencia internacional consagrada a la edición digital y al sabotaje de una edición clásica que se juzgaba moribunda: Tools of Change for Publishing. El programa fijado por O'Reilly retomaba con mucha fidelidad el de la Web 2.0. Ahora bien, de 2006 a 2013, fecha en la que fueron desprogramados, los TOC se volvieron progresivamente ecologías institucionales, es decir, lugares de cruce entre actores muy diferentes (JAHJAH 2014). Los temas abordados iban del análisis estadístico de datos de lectores a su gestión en

14 Fuente: "Kobo CEO on the Future of E-Readers and Google Books", 7 diciembre de 2012, <http://www.forbes.com/sites/elizabethwoyke/2011/07/12/kobo-ceo-on-the-future-of-e-readers-andgoogle-books/. Consultado a 9/9/2014>.

${ }^{15}$ Twas the night before iTablet, when all through the publishing house/ Not an executive was sleeping, they reached for their mouse [...] "Hey developers, marketers, biz dev, get on your game!"/Random House, Harper, Simon \& Schuster,/Now's the time to voice all the power you can muster;/eBooks are here! eBooks for all ! Michael Serbinis, "Twas The Night Before iTablet", 26 enero de 2010, Serbinis retoma en efecto la estructura del poema de Clément Clarke Moore (1779-1863), "A Visit From St. Nicholas". <http://serbinis.blogspot.fr/2010/01/twas-night-before-itablet.html. Fuente consultada a 10/2/2014>.

${ }^{16}$ Tim O'Reilly, "What Is Web 2.0. Design Patterns and Business Models for the Next Generation of Software", en línea: <http://oreilly.com/Web2/archive/what-is-Web-20.html>. Fuente consultada a $14 / 9 / 2014$.

Texto Digital, Florianópolis, Santa Catarina, Brasil, v. 12, n. 2, p. 96-123, jul./dez. 2016. ISSNe: 1807-9288. 
comunidades, así como a la necesidad de adaptar las formas de la cultura impresa (página, índice, índice alfabético, etc.) a los desafíos planteados por las pantallas.

La mayoría de los actores de las redes sociales del libro que hemos encontrado en este artículo participaron en estos debates. El 17 de febrero de 2011, Sol Rosenberg de Copia intervino en la edición 2011 de Tools of Change para presentar la empresa en la que trabaja en cuanto que responsable de la adquisición y promoción de contenidos editoriales. Empezó proyectando un vídeo promocional de Copia, que ponía en escena a un intelectual leyendo a partir de soportes digitales mientras escucha música clásica:

Imagen 30 - Vídeo promocional n¹ de Copia en Tools of Change 2011

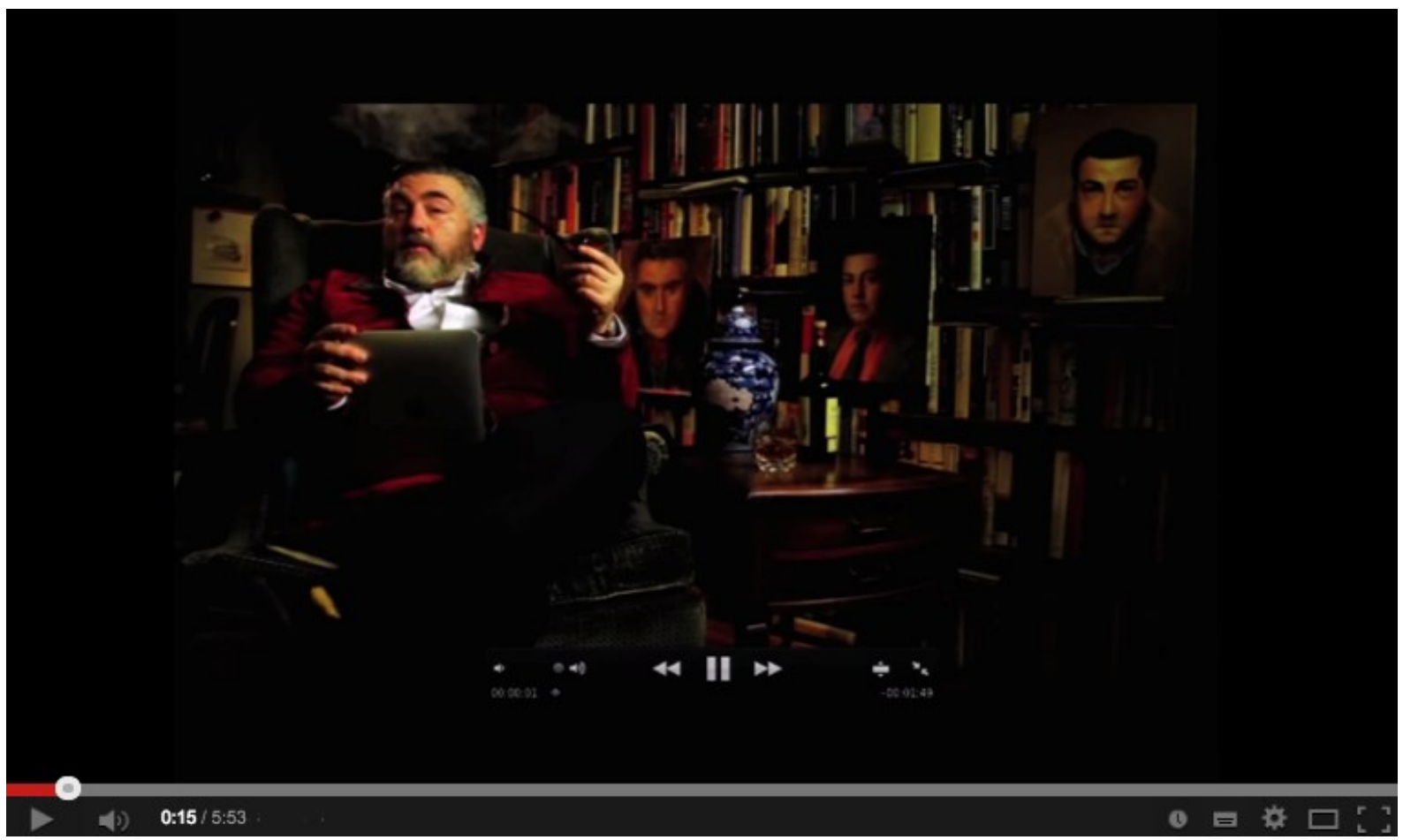

Fuente: intervención de Sol Rosenberg en Tools of Change 2011, 17 febrero de 2011, $<$ https://www.youtube.com/watch?v=HoEexVaYJKs>. Captura de pantalla a 3/09/2014.

Copia no se dirigía sin embargo a intelectuales, sino a un público relativamente amplio. El personaje es explícito en este aspecto: "Copia no es sólo para intelectuales como yo, sino para cualquiera". A partir de entonces, el ceremonial movilizado aparece como un conjunto de signos estereotipados (la música que se escucha es Carmen, que forma parte de nuestra memoria colectiva y que podemos 
casi todos identificar, o al menos tararear) cuya función principal es demostrar que las prácticas letradas son "extrapolables". Así, la pipa, el traje, la biblioteca y el mobiliario, que connotan la cultura burguesa de finales del XIX, se asocian rápidamente a una serie de iconos típicos y propios de la cultura digital:

Imagen 31 - Vídeo promocional n² de Copia en Tools of Change 2011

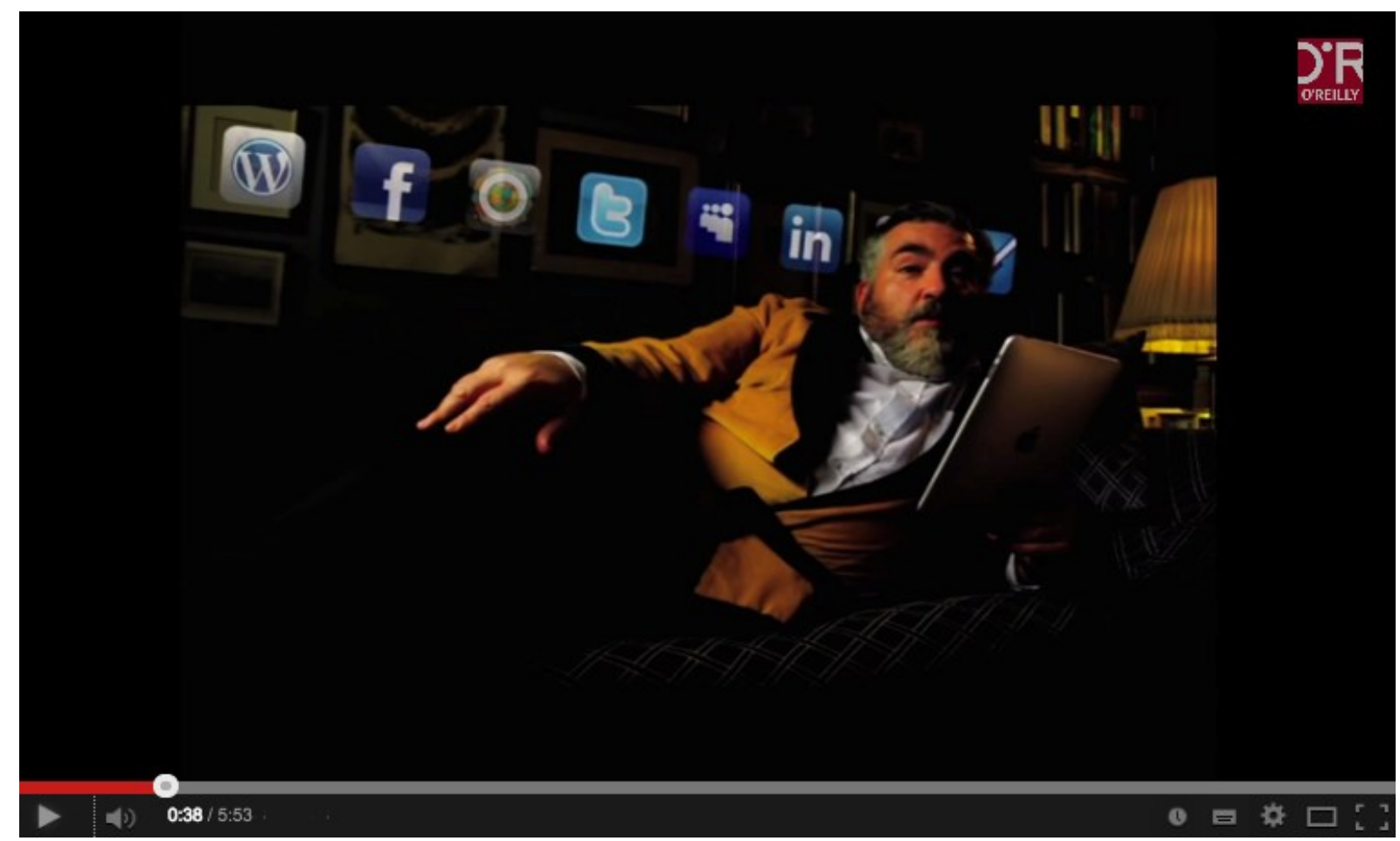

Fuente: intervención de Sol Rosenberg en Tools of Change 2011, 17 febrero de 2011, <https://www.youtube.com/watch?v=HoEexVaYJKs>. Captura de pantalla a 3/09/2014.

La promoción de Copia se hace entonces a partir de la dialéctica de la estabilidad y del cambio, que corresponde bien al programa fijado por O'Reilly: llevar a los editores a desplazarse progresivamente. Gracias a Copia, afirmaba en su presentación Sol Rosenberg, los editores tendrían por fin los medios de poner al día sus libros, juzgados inertes y propios a la cultura impresa.

Este universo discursivo no es sin embargo homogéneo; los actores tienen tendencia a posicionarse unos respecto a otros: se trata entonces más bien de un campo discursivo y comunicacional que podría definirse como luchas de legitimidad y justificaciones expresadas por medio de signos. Para identificar estas luchas, la conferencia Tools of Change, que privilegia al contrario la homogeneidad de 
posiciones, ya no basta; habrá entonces que redirigirse hacia el conjunto de canales de comunicación utilizados por los diseñadores de las redes del libro. Así, en una entrevista concedida a Loïc Le Meur en noviembre de 201177, quien le hacía reconocer que los programas de lectura tienen tendencia a distraer al lector, el cofundador de Readmill fue categórico: "No nos interesa para nada la experiencia de la lectura. Se trata del diseño. No hay que molestar al lector demasiado. [...] No hay ningún chat." Así se apuntaba claramente a Kobo y a sus funcionalidades sociales: "chat" en los márgenes como sistema de gratificaciones tras cada acción ejecutada. La ruptura se sitúa igualmente en el reparto de datos. Readmill explicaba así a la revista alemana Buchreport que, contrariamente a Amazon, la empresa compartía los datos de los usuarios (la transformación de rastros en indicaciones econométricas: tiempo de lectura, etc.) para ayudar a los editores a comprender mejor sus comportamientos y a tomar buenas decisiones. Readmill se presentó desde entonces bajo el eslogan siguiente "crunching your reading data" 18 . Una manera hábil de justificar su iniciativa de colectar inscripciones. Dicho de otro modo: como Proteo, estos dispositivos tienen la capacidad de transformarse, integrando las críticas que se les podría formular para adaptarlas a su favor.

\section{Conclusión}

Desde su producción a su circulación en otros espacios mediáticos, las anotaciones están siempre enmarcadas: pese a las tentativas de los dispositivos para borrar las huellas de intervención, llevan en ellas las condiciones técnicas, enunciativas, semióticas de su elaboración. En este horizonte industrial, las anotaciones no son sino recursos productivos que sirven para alimentar las bases de datos. Frente a esta industrialización de las formas escriturales, las instituciones y las organizaciones reflexionan sin embargo sobre las soluciones abiertas (como Textus - Hypothes.is), capaces de asegurar la compatibilidad entre los diferentes dispositivos y, por tanto, la circulación de conocimientos. Amistosos, los programas de anotación se convertirían entonces en recursos de nuestra geografía íntima

\footnotetext{
17Fuente: entrevista de Henrik Berggren por Loïc Le Meur, 12 novembre 2011, https://www.youtube.com/watch?v=BuZ6DDwBuzg. Captura de pantalla a 30/08/2014.

${ }^{18} \mathrm{En}$ efecto, es así que el co-fundador de Readmill presentaba su empresa a Loïc Le Meur en noviembre de 2011. Fuente: https://www.youtube.com/watch?v=BuZ6DDwBuzg, a 30/08/2014.
}

Texto Digital, Florianópolis, Santa Catarina, Brasil, v. 12, n. 2, p. 96-123, jul./dez. 2016. ISSNe: 1807-9288. 
donde uno vendría a "esconderse, a recogerse en sí mismo" (Bachelard, 2011 [1957], p. 130) para decir "[nuestras] carreteras, [nuestros] cruces, [nuestros] bancos". Recordando y trabajando los lazos etimológicos entre el margen, la marca y la marcha ${ }^{19}$, tendríamos los medios para abogar a favor del grafiti, es decir, de la ociosidad, de la ensoñación, véase de la bufonería en los márgenes de la comicidad.

\section{THE SITUATION OF ANNOTATION IN READERS' SOCIAL NETWORKS ON INTERNET (2007- 2014)}

ABSTRACT: Since 2008, social reading networks of a new kind have grown (BookGlutton, Kindle Highlights, Readmill, etc.). They offer their users the possibility to annotate books and share their highlights through electronic devices (tablets, computer, etc.) or writing interfaces. These marginal writings (marginalia) are collected by the companies and exploited in various ways (data-users, 'enhanced books', etc.). This article tries to understand why annotation is the object of such interest by some industrialists of reading and how they exploit it.

KEYWORDS: Social Network. Reading. Highlighting. Digital Books. Internet.

\section{Referencias}

BASSEZ Danielle, 2006, Écrits dans les marges : de la pratique du gribouillage comme art gourmand de la lecture, Devesset, Cheyne Éditeur.

Beguin-VerbRugge, 2006, Images en texte, Images du texte. Dispositifs graphiques et communication écrite, Villeneuve d'Ascq, Septentrion.

BOULLIER Dominique, 2013, "Profils, alerte et vidéo " : de l'outre-lecture à la fin de la lecture »?, dans Christophe Evans (dir.), Lectures et lecteurs à l'heure d'Internet. Livre, presse, bibliothèque, París, Cercle de la librairie, p. 41-58.

BOUQUILLION Philippe et MATTHEWS Jacob Thomas, 2010, Le Web collaboratif : mutations des industries de la culture et de la communication, Grenoble, Presses universitaires de Grenoble.

Brayman Hackel Heidi, 2009, Reading Material in Early Modern England. Print, Gender, and Literacy, Cambridge (Reino Unido), Cambridge University Press.

19 "Margen" viene del latín "margo" (1225), "borde", asimismo derivado del término "mark" (signo), que habría dado la forma germánica "marka", "frontera", "marcha", "marca" (cfr. Cormier, 2005 et Glaudes, 1988). 
BRINGAY Sandra, BARRY Catherine et CHARLET Jean, 2004, " Les documents et les annotations du dossier patient hospitalier », Information-Interaction-Intelligence, 4 (1), p. 191-211.

CANDEL Étienne, 2007, « Autoriser une pratique, légitimer une écriture, composer une culture : les conditions de possibilité d'une critique littéraire participative sur Internet. Étude éditoriale de six sites amateurs », Tesis doctoral, Paris IV Sorbonne. CHÂTELAIN Jean-Marc, 1999, " Humanisme et culture de la note », Le Livre annoté, Revue de la Bibliothèque nationale de France, p. 26-37.

CORMIER Marie-Christine, 2005, «Regard géographique sur les marges » dans Philippe Forest et Michelle Szkilnik (dir.), Théorie des marges littéraires, Nantes, Éditions Cécile Defaut.

DoueIHI Milad, 2011, Pour un humanisme numérique, París, Seuil.

GeORGES, Fanny, 2011, « L’identité numérique sous emprise culturelle. De l'expression de soi à sa standardisation », Les Cahiers du numérique, 1 (7), p. 31-48.

GLAUDES Pierre, 1988, "Écriture marginale et genèse symbolique », dans François Marotin (ed.), La Marge, Actes du colloque de Clermont-Ferrand (1986), Publicación de la Facultad de Letras et Ciencias humanas de la Universidad Blaise Pascal, p. 193.

JACKSON H. J, 2002, Marginalia : Readers Writing in Books, New Haven, Yale University Press (formato Kindle). 2005, Romantic Readers : The Evidence of Marginalia, New Haven, Yale University Press, 2005.

JAHJAH Marc, "Les marginalia de lecture dans les "réseaux sociaux" du livre (20082014) : mutations, formes, imaginiares », 2014.

- « Des énoncés sans énonciateurs ? Du surlignement à la citation dans le Kindle d'Amazon », Semen, primavera 2016.

JEANNERETYves, 2012, "Écriture et médias informatisés », dans Anne-Marie Christin (dir.), Histoire de l'écriture : de l'idéogramme au multimédia, Paris, Flammarion, p. 395-402.

LERER Seth, 2012, « Devotion and Defacement : Reading Children's Marginalia », Representations, 118 (1), p. 126-153.

MoEGLIN Pierre, 2005, Outils et médias éducatifs. Une approche communicationnelle, Grenoble, Presses de l'Université de Grenoble.

MONNIN Alexandre, 2013, "Les ressources, des ombres récalcitrantes ", SociologieS, 25 junio 2013.

NiKolova-Houston Tatiana, 2009, « Marginalia and Colophons in Bulgarian Manuscripts and Early Printed Books », Journal of Religious \& Theological Information, 8, p. 65-91. 
RAGAZZOLI Chloé, 2011, « Lire, écrire, survivre : les graffiti de scribes au Nouvel Empire », dans christian Jacob (dir.) Les Lieux de Savoir, t 2, París, 2011, p. 290311.

SCHOTT Christine Marie, 2012, « Intimate Reading: Marginalia in Medieval Manuscripts », PhD, University of Virginia.

ShERMAN William H., 2009, Used Books. Marking Readers in Renaissance England, Pennsylvanie, University of Pennsylvania Press.

TURA Adolfo, 2005, « Essai sur les marginalia en tant que pratique et documents » dans Daniel Jacquart et Danielle Burnett (dir.), Scientia in Margine. Etudes sur les marginalia dans les manuscrits scientifiques du Moyen Âge à la Renaissance, Ginebra, Droz, p. 261-380.

Wolfe Joanna L. et NeUWIRTH Christine M., 2001, « From the Margins to the Center The Future of Annotation », Journal of Business and Technical Communication, 1 julio 2001, vol. 15, n³, p. 333-371.

Recebido em: 01/12/2016.

Aceito em: 08/12/2016. 